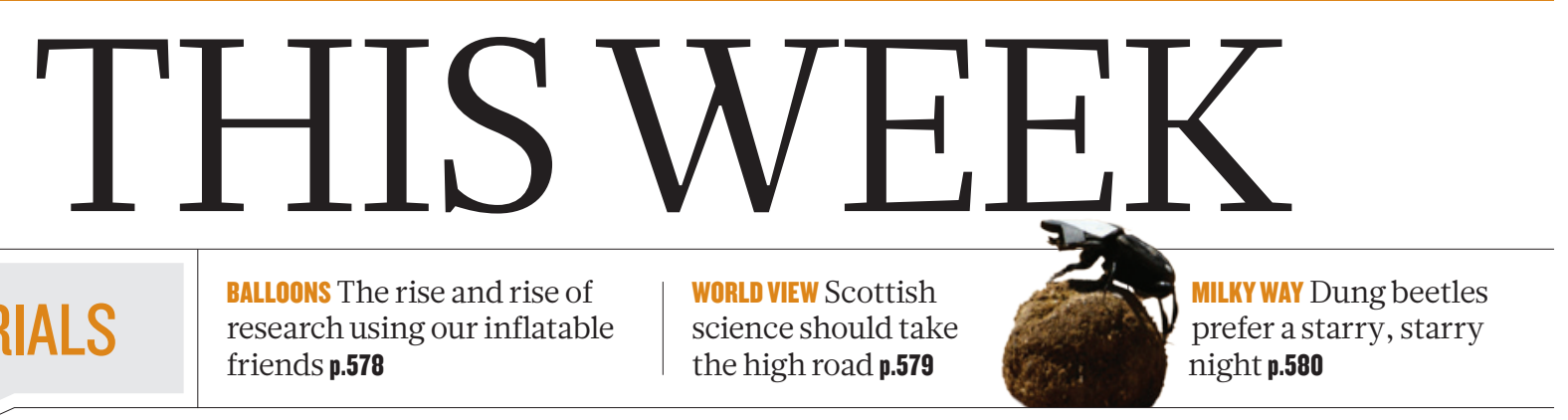

EDITORIALS research using our inflatable friends $\mathbf{p . 5 7 8}$

science should take the high road $\mathbf{p . 5 7 9}$

\title{
Twice the price
}

\section{Governments and funding agencies must do more to prevent the awarding of grants to research projects with significant overlap.}

$\mathrm{T}$ There is nothing more central to the modern world of international science than the research grant. And with government budgets squeezed, there is nothing more important than making sure that what money remains for project-based science is spent wisely. So scientists everywhere should be disturbed that two separate pieces in Nature this week report on the lack of oversight of potential waste and overlap between research grants.

Similarities between a number of US grants were first flagged up by a Comment on bioinformatics research (see page 599). Two reporters then requested more details under the US Freedom of Information Act (see page 588). Just as important as what we found is what we couldn't find.

It turns out that although some individual agencies maintain databases, in most countries - perhaps even all - there is no centralized government-maintained online database of all state-funded research projects. This week's findings come from three US government agencies that do keep such records: the US Army's Congressionally Directed Medical Research Programs, the National Institutes of Health and the National Science Foundation (NSF). There is no reason to think that these agencies are not representative. So the findings, limited though they are, warrant careful attention.

A review of 22 pairs of seemingly similar grant files revealed many that appeared to overlap, with specific aims, hypotheses and methods that contained large sections of duplicated text. Where we saw different text, we were careful to analyse whether it had a central role - for example, whether it showed study of an entirely different protein or nanomaterial by an identical method. In many instances, the different text didn't seem to fully distinguish projects from each other. In some cases, researchers and agencies did provide explanations of why seemingly similar grants did not overlap, and these are given in our News story. But the exercise nevertheless exposed some loopholes.

First, checks on overlap are mostly trust-based. The responsibility lies with researchers and institutions to declare when they have been awarded similar grants. Yet some that we reviewed apparently had not done so, or not in a timely fashion. Similarly, researchers sometimes declared "overlap: none" between applications when to us and sometimes even to agency staff - it seems that there was some overlap. Although much of science is trust-based, there is no reason, with the advent of text-similarity software and electronic databasing, for agencies not to be proactive (in the way the bioinformaticians who prepared the Comment piece were) and ask for more original documentation when large segments of grants seem identical. Indeed some officials, we could see from the files, are already doing this.

Second, concurrent submissions of similar grant applications to US agencies do not have to be declared to every agency involved until funding decisions are made. The NSF does require declaration on submission when applications are identical, but we found that in most cases they were only similar. It is worth considering whether all

submissions should be declared up front, in the same way that college and graduate-school applications in the United States and the United Kingdom include information on all applications made by a student. This might help reviewers to better understand each researcher's range of interests, as well as helping agencies to avoid overlap. Agencies should adopt and adapt the NSF checkbox to applications so that

"There is no reason, with the advent of text-similarity software, for agencies not to be proactive." grant funding online, where past and current awards can be easily found by scientific search terms, researchers names, institution, city and agency. Having created such databases, funding agencies should maintain them.

The US Department of Energy recently took down a useful project database from its website, it says, to save money. But as this information increasingly already exists in-house, the costs of making it public should be modest. The benefit would be that researchers, and others, can see quickly what has been funded and where future efforts are needed. In addition, such a facility would allow the public to understand and scrutinize where its money goes. Of course, the idea of anyone being able to survey funding decisions at a click of a button may make some officials uncomfortable, but those who do a good job to balance and police their portfolios will get the credit they deserve.

\section{Change for good}

The United States must boost energy spending to make its mark on the climate debate.

$\mathrm{E}$ nvironmentalists lauded US President Barack Obama when he raised the issue of global warming in his second inaugural address on 21 January, but the truth is that he said nothing new. Obama kept it simple, short and vague, discussing climate change as a moral imperative while declaring clean energy a battleground for innovation. It was a generic vision for a pragmatic president, which is to his credit. But if Obama truly wants to leave his mark on the climate debate, he will need to break out of the mould and lay the foundation for something larger.

His initial focus is likely to be a trio of energy decisions, on a pipeline 
and a pair of rules for power plants (see page 590). The first decision relates to the Keystone XL pipeline, which would carry oil from the Canadian tar sands to the Gulf Coast refineries. The other two are climate regulations that focus on new and existing power plants. Combined, these two rules could prevent any conventional coal-fired plant from being built in the United States, while giving electricity generation another boost towards using plentiful natural gas.

They give Obama an early opportunity to build some goodwill across the political spectrum. First, the administration should issue strong regulations for power plants and send a message to the coal industry: clean up or fade away. The energy utilities will duly cry foul, but the same companies are already powering down old and inefficient coal-fired power plants in favour of natural-gas plants. Why? Because natural gas is cheap and burns more cleanly than coal, helping companies to meet increasingly stringent air-quality regulations.

Second, regarding the Keystone pipeline, the administration should face down critics of the project, ensure that environmental standards are met and then approve it. As Nature has suggested before (see Nature 477,249; 2011), the pipeline is not going to determine whether the Canadian tar sands are developed or not. Only a broader - and much more important - shift in energy policy will do that. Nor is oil produced from the Canadian tar sands as dirty from a climate perspective as many believe (some of the oil produced in California, without attention from environmentalists, is worse). Tar-sands development raises serious air- and water-quality issues in Canada, but these problems are well outside Obama's jurisdiction.

By approving Keystone, Obama can bolster his credibility within industry and among conservatives. The president can also take advantage of rising domestic oil and gas production to defuse concerns over energy security. And the fact that US emissions are apparently dropping, thanks to the economic crisis and the ongoing shift from coal to gas for electricity generation as well as state and federal policies, further

plays into his hands. But all will be for naught unless the president can build on these trends and somehow reset the climate discussion.

The foundation for this re-engagement could be a good oldfashioned strategic research and development (R\&D) programme for clean energy. The United States' current US\$4-billion energy-

"Driving down carbon energy might even unlock political solutions." the cost of low-

research portfolio is not up to the task, and almost everybody recognizes as much. In 2010, the President's Council of Advisors on Science and Technology recommended boosting the federal energy-innovation budget to $\$ 16$ billion. The Brookings Institution, a Washington DC think tank, has argued that even a small carbon tax could provide up to $\$ 30$ billion annually for energy research. If these numbers seem high, keep in mind that in fiscal year 2012, the United States spent an estimated $\$ 73$ billion on defence-related R\&D and more than $\$ 31$ billion on health-related R\&D.

These ideas have been floating around in the scientific community for some time. Some extra money will be needed, but organizations such as the Clean Air Task Force, based in Boston, Massachusetts, are looking at ways to better direct energy subsidies and use existing government spending to drive new markets for advanced technologies.

The Obama administration might be able to put the United States on track to meet its Copenhagen commitment to reduce emissions to $17 \%$ below 2005 levels by 2020 . It can seek immediate climate benefits by pushing international initiatives that reduce emissions of black carbon, methane and other powerful greenhouse gases. But given the current political deadlock over climate regulation on Capitol Hill, Obama must also develop a long game that will help to get the United States, and hopefully the world, to where it wants to be several decades from now. Driving down the cost of low-carbon energy might even unlock political solutions in the future.

\section{Inflatable friends}

\section{Research balloons have taught us much about the atmosphere, and could now fly into space.}

\section{$\mathrm{T}$} he Swiss physicist Auguste Piccard will be recognizable to anyone who grew up reading the comic-book adventures of Tintin. After spotting Piccard on a Brussels street, the Belgian cartoonist Hergé used his striking appearance as inspiration for Tintin's scientific friend Professor Cuthbert Calculus. But Piccard should also be recognized for his advancement of a scientific platform that remains important today: the research balloon.

Piccard was an inventor and explorer. In 1930, he designed a pressurized steel gondola that could carry passengers and laboratory equipment beneath a balloon. The vehicle would eventually inspire his deep-ocean bathyscaphe, but in 1931 Piccard and his colleague Paul Kipfer used it to explore the atmosphere, reaching 15,785 metres and measuring cosmic rays. It was a fitting experiment: cosmic rays were discovered in 1912 when Austrian physicist Victor Hess carried electrometers to about 5,000 metres in a perilous open basket beneath a balloon.

Balloons have gone higher and farther for science ever since. Just last week, a NASA long-duration balloon broke the record for flight length when it clocked up its 46th day spinning in the high winds and chilly skies above the South Pole. No scientist hangs beneath this one, but the goal remains the same as in Piccard's day. The balloon floats some 39 kilometres up and carries the Super Trans-Iron Galactic Element Recorder, which sifts through high-energy cosmic rays, looking for rare heavy elements.

Balloons could go higher still. This month, NASA raised the prospect that one could be (gently) bolted onto the side of the International Space Station. The agency calls it an expandable activity module; the media used the terms giant space balloon and bouncy castle. Either way, this balloon (expandable activity module) would not simply support science - it could house it. The agency is in talks with the module's developer, Bigelow Aerospace of North Las Vegas, Nevada, as to how it could test the module as a living and working habitat in orbit. If they can repel the radiation and pointy micrometeorites that are a hazard of life in space, then inflatable modules could be used to construct whole space stations. The appeal is obvious: such equipment would be compact and therefore cheap to get off the ground and to construct in orbit.

Balloons have been launched into space before. The twin European Vega missions of the mid-1980s deployed one each to hang in the Venusian sky, where they measured wind speed and cloud density. Balloons have even been used to launch rockets towards space. The 'rockoons' developed by James Van Allen at the University of Iowa in Iowa City in the 1950s were balloons that carried sounding rockets into the atmosphere and then launched them to ever higher altitudes. When the rockets fell back to Earth, they brought hints of layers of trapped radiation beyond the atmosphere, which became known as Van Allen belts.

Balloons have carried cameras and telescopes to probe various regions of the electromagnetic spectrum, and sent plants and animals to the stratosphere. They have been made of plastic and rubber, and used alone or in fleets. They remain silent and surprisingly stable platforms for science. And for more than science - a series of US research balloons used to study pollution in the 1970s doubled as kinetic art. They are $\rightarrow$ NATURE.COM To comment online, click on Editorials at: go.nature.com/xhunqu important testing grounds for instruments and techniques that will one day fly in space. "Exploration is the sport of the scientist," Piccard once said. The humble balloon has more than played its part in both, and will continue to do so.. 